\title{
“ФЛОРА РОССИИ” НА ПЛАТФОРМЕ іNATURALIST: БОЛЬШИЕ ДАННЫЕ О БИОРАЗНООБРАЗИИ БОЛЬШОЙ СТРАНЫ
}

(C) 2020 г. А. П. Серегин ${ }^{1, ~ *, ~ Д . ~ А . ~ Б о ч к о в ~}{ }^{1}$, Ю. В. Шнер ${ }^{1}$, Э. В. Гарин ${ }^{2}$, С. Р. Майоров ${ }^{1}$, П. В. Голяков ${ }^{3}$, Б. В. Большаков ${ }^{4}$, В. Е. Прохоров ${ }^{5}$, М. М. Маллалиев ${ }^{6}$, Г. М. Виноградов ${ }^{7}$, Александр Л. Эбель ${ }^{8}$, Е. С. Каширина ${ }^{9}$, О. В. Бирюкова ${ }^{10}$, О. П. Курякова ${ }^{4}$, С. В. Мирвода ${ }^{11}$, А. Н. Химин ${ }^{12}$, Р. А. Муртазалиев ${ }^{6}$, В. Н. Зеленкова ${ }^{13}$, С. В. Дудов ${ }^{1}$, М. С. Горбунова ${ }^{14}$, С. В. Герасимов ${ }^{15}$, Алексей Л. Эбель ${ }^{16}$, В. П. Травкин ${ }^{4}$, О. А. Чернягина ${ }^{17}$, Е. А. Разина ${ }^{4}$, А. П. Зырянов ${ }^{4}$, Д. В. Третьякова ${ }^{18}$, С. А. Леднев ${ }^{1}$, В. Ю. Теплоухов ${ }^{19}$, Д. В. Кузменкин ${ }^{3}$, М. М. Кривошеев ${ }^{20}$, Е. С. Попов ${ }^{21}$, Р. Р. Султанов ${ }^{4}$, Ю. М. Басов ${ }^{4}$, К. В. Дудова ${ }^{1}$, Д. В. Тишин А. А. Яковлев ${ }^{4}$ Ю. В. Данилевский ${ }^{4}$, И. Н. Поспелов ${ }^{22}$, А. Н. Кандаурова ${ }^{4}$, С. Б. Кутуева ${ }^{23}$, Д. А. Юмагулов ${ }^{4}$, К. В. Самодуров ${ }^{4}$, Л. Я. Смирнова ${ }^{4}$, В. В. Бурый ${ }^{24}$, В. Е. Юсупов ${ }^{4}$, Д. В. Епихин ${ }^{25}$, Т. Г. Репина ${ }^{4}$, Е. И. Богинский ${ }^{4}$, А. В. Дубынин ${ }^{26}$, А. В. Коробков ${ }^{4}$, Д. В. Нестеркова 27 , А. В. Полуянов ${ }^{28}$, А. В. Данилин ${ }^{29}$, А. Н. Ефремов ${ }^{30}$, Л. В. Пожидаева ${ }^{31}$, А. В. Верхозина ${ }^{32}$, Ю. А. Постников ${ }^{14}$, Е. А. Линник ${ }^{4}$, И. А. Кобузева ${ }^{4}$, С. В. Прокопенко ${ }^{33}$, Е. А. Шумихина ${ }^{34}$, М. А. Кушунина ${ }^{1}$, И. В. Кузьмин ${ }^{35}$, Л. М. Разран ${ }^{36}$, Д. В. Сухова ${ }^{1}$, А. В. Попов ${ }^{37}$

${ }^{1}$ Московский государственный университет им. М.В. Ломоносова Ленинские горы, 1, Москва, 119991 Россия

${ }^{2}$ Институт биологии внутренних вод им. И.Д. Папанина РАН пос. Борок, Ярославская обл., 152742 Россия

${ }^{3}$ Государственный природный заповедник “Тигирекский” ул. Никитина, 111-42, Барнаул, 656043 Россия

${ }^{4}$ Независимый исследователь, Москва, Россия

${ }^{5}$ Казанский (Приволжсский) федеральный университет ул. Кремлевская, 18, Казань, 420100 Россия

${ }^{6}$ Горный ботанический сад ДФИЦ РАН ул. М. Гаджиева, 45, Махачкала, 367000 Россия

${ }^{7}$ Институт океанологии им. П.П. Ширшова РАН Нахимовский просп., 36, Москва, 117997 Россия

${ }^{8}$ Томский государственный университет просп. Ленина, 36, Томск, 634050 Россия

${ }^{9}$ Филиал МГУв г. Севастополе

ул. Героев Севастополя, 7, Севастополь, 299001 Россия

${ }^{10}$ Нижеггородский государственный университет им. Н.И. Лобачевского nросn. Гагарина, 23, Нижний Новгород, 603950 Россия

${ }^{11}$ СХ ПАО “Белореченское”

пос. Белореченский, Иркутская обл., 665479 Россия

${ }^{12}$ Павловская средняя общеобразовательная школа № 2

ул. Кирова, 27/1, Павловск, Воронежская обл., 396420 Россия

${ }^{13}$ Белгородский государственный национальный исследовательский университет ул. Победы, 85, Белгород, 308015 Россия

${ }^{14}$ Московский педагогический государственный университет ул. М. Пироговская, 1, Москва, 119435 Россия

${ }^{15}$ Республиканский детский эколого-биологический центр просп. Октября, 4, Уфа, 450001 Россия

${ }^{16}$ Алтайский государственный университет просп. Ленина, 61, Барнаул, 656049 Россия

${ }^{17}$ Камчатский филиал Тихоокеанского института географии ДВО РАН ул. Партизанская, 6, Петропавловск-Камчатский, 683000 Россия

${ }^{18}$ Тольяттинский государственный университет

ул. Белорусская, 14, Тольятти, Самарская обл., 445020 Россия 
${ }^{19}$ Главное управление лесного хозяйства Омской области ул. Куйбышева, 63, Омск, 644001 Россия

${ }^{20}$ Башкирский государственный университет ул. Заки Валиди, 32, Уфа, 764500 Россия

${ }^{21}$ Ботанический институт им. В.Л. Комарова РАН

ул. Профессора Попова, 2, Санкт-Петербург, 197376 Россия

${ }^{22}$ Институт проблем экологии и эволюции им. А.Н. Северцова РАН Ленинский просп., 33, Москва, 119017 Россия

${ }^{23}$ Рыбинский историко-архитектурный и художественный музей-заповедник

Волжсккая наб., 2, Рыбинск, Ярославская обл., 152901 Россия

${ }^{24}$ Белорусский государственный университет

просп. Независимости, 4, Минск, 220030 Белоруссия

${ }^{25}$ Крымский федеральный университет им. В.И. Вернадского

просп. Академика Вернадского, 4, Симферополь, 295007 Россия

${ }^{26}$ Открытая лаборатория природоохранной биологии

ул. Иртышская, 33, Новосибирск, 630060 Россия

${ }^{27}$ Институт экологии растений и животных УрО РАН

ул. 8 Марта, 202, Екатеринбург, 620144 Россия

${ }^{28}$ Курский государственный университет

ул. Радищева, 33, Курск, 305000 Россия

${ }^{29}$ Национальный исследовательский технологический университет “МИСиС” Ленинский просп., 2, Москва, 119049 Россия

${ }^{30}$ Проектный институт реконструкции и строительства объектов нефти и газа ул. Красный Путь, 153/2, Омск, 644033 Россия

${ }^{31}$ Алтайская краевая общественная организация “Экологический актив” ул. А. Петрова, 247а-44, Барнаул, 656065 Россия

${ }^{32}$ Сибирский институт физиологии и биохимии растений СО РАН ул. Лермонтова, 132, Иркутск, 664033 Россия

${ }^{33}$ ФНЦ Биоразнообразия наземной биоты Восточной Азии ДВО РАН просп. 100 лет Владивостоку, 159, Владивосток, 690022 Россия

${ }^{34}$ ООО ГП “Промнефтегазэкология” ул. Республики, 207, Тюмень, 625019 Россия

${ }^{35}$ Тюменский государственный университет ул. Володарского, 6, Тюмень, 625003 Россия

${ }^{36}$ Университет природных ресурсов и наук о жизни Gregor-Mendel-Straße, 33, Вена, A-1180, Австрия

${ }^{37}$ Волгоградский государственный социально-педагогический университет просп. Ленина, 27, Волгоград, 400066 Россия

*E-mail: botanik.seregin@gmail.com

Поступила в редакцию 20.01.2020 г.

После доработки 04.02.2020 г.

Принята к публикации 11.02.2020 г.

\begin{abstract}
Проект “Флора России” на международной платформе iNaturalist объединил профессиональных ученых и любителей природы со всей страны. В сборе данных участвует свыше 3800 человек. За один год участники собрали свыше 220000 фотонаблюдений по 5689 видам флоры России. Это третий по объему массив открытых пространственных данных о биоразнообразии страны (и второй по распространению растений), ведущий источник данных по современному состоянию флоры. Для большинства адвентивных видов полученные карты являются наиболее достоверными картографическими изображениями ареалов в пределах России. Для многих муниципальных районов полученные списки видов представляют собой самую полную и точную флористическую информацию. Все данные проекта находятся в открытом доступе и могут свободно использоваться в научной, поисковой и природоохранной деятельности.
\end{abstract}

DOI: $10.31857 / \mathrm{S} 0044459620030070$

Изучение биоразнообразия остается одной из наиболее популярных областей биологии. По всему миру в рутинной ежедневной документа- ции встреч отдельных видов растений, животных и грибов к профессиональным ученым присоединяется все больше натуралистов-любителей. По 
данным портала GBIF - Global Biodiversity Information Facility (https://www.gbif.org/), который объединяет в качестве единой точки доступа 50 тысяч баз данных, пять самых крупных массивов электронных данных о биоразнообразии мира создаются именно в результате активной работы непрофессиональных наблюдателей (Vries, 2018; Levatich, Padilla, 2019; Nyegaard, 2019; Shah, Coulson, 2020; The Norwegian..., Hoem, 2020) - особенно по птицам, данные о которых на сегодняшний день составляют $65 \%$ всего GBIF. Работа непрофессиональных наблюдателей, в том числе в непосредственном контакте с учеными, формирует отдельную сферу научной деятельности, которая получила название "citizen science" ("гражданская наука") (Bonney et al., 2009; Silvertown, 2009; Hand, 2010, и др.).

Задачи, которые стоят перед гражданской наукой в мире, не “спускались" сверху, а зарождались как запросы ученых к существующим сообществам. В результате этого общения появлялись совместные проекты, где их участники продолжали решать свои задачи, а ученые - свои. Область применения массовой гражданской науки не очень широка, она заключается в сборе или первичной обработке (оцифровке) данных, которые участники добывают массово, но при этом очень простыми (а значит понятными) методами. Гражданская наука дает именно новые данные (в том числе "большие данные"), а научные знания получаются из них в результате последующего осмысления информации методами анализа и синтеза. Таким образом, гражданская наука не может заменить профессиональную науку, но может стать ее опорой в некоторых областях.

Среди ведущих поставщиков открытых данных о биоразнообразии мира единственной универсальной базой данных, охватывающей весь земной шар и все группы живых организмов, является платформа iNaturalist, которая позиционируется как один большой проект в области гражданской науки. Данные, собранные на iNaturalist, используются в сотнях научных статей (White et al., 2015; Fourcade, 2016; Spear et al., 2017; Longbottom et al., 2018; Ocampo-Peñuela et al., 2018, и др.).

\section{МАТЕРИАЛЫ И МЕТОДЫ}

Особенности платформы для сбора данных. Любой пользователь может зарегистрироваться в качестве “наблюдателя" (observer) на платформе iNaturalist. Он получает возможность загружать через свою учетную запись наблюдения, используя бесплатные приложения "iNaturalist" и "Seek" или сайт https://www.inaturalist.org/. В работу платформы вовлечено 835000 наблюдателей, в том числе 6380 наблюдателей, имеющих хотя бы одно наблюдение с территории России (данные на 08.01.2020).

Для того, чтобы удовлетворять минимальным требованиям для дальнейшего научного использования, наблюдение должно: (1) иметь дату; (2) иметь геопривязку - координаты места встречи; (3) содержать фотографию/серию фотографий или аудиозапись голоса (для животных); (4) фотография должна быть сделана автором; (5) организм должен быть снят в диком состоянии. При выполнении этих требований наблюдение попадает в число неопределенных независимо от того, назвал ли автор сфотографированный организм или нет. Как только фотографию до уровня вида (в некоторых случаях до рода) определят два эксперта (одним из них может быть автор наблюдения), она получает “исследовательский уровень”, т.е. переходит в категорию верифицированных наблюдений. Дальнейшие определения/переопределения могут вывести наблюдение из этой категории. Некачественные фотографии или группы, для определения которых нужны микроморфологические, анатомические или генетические признаки, в абсолютном большинстве случаев не достигают “исследовательского уровня”.

Для своих наблюдений авторы выбирают лицензию - разрешаемый автором тип дальнейшего использования его данных. При выборе одной из свободных лицензий Creative Commons (CC0, CC-BY, CC-BY-NC) данные, достигшие "исследовательского уровня", автоматически экспортируются в GBIF и окончательно включаются в научный оборот. На 08.01.2020 база данных iNaturalist содержала 30.5 млн наблюдений, отвечающих минимальным требованиям качества, из которых 18.6 млн достигли “исследовательского уровня" (61\%). Однако лишь 12.5 млн наблюдений (41\%) имели свободные лицензии.

Искусственный интеллект. Особенностью iNaturalist является внедрение самообучающегося искусственного интеллекта (ИИ) (Horn et al., 2017, 2018a, b; Cui et al., 2018), который предлагает пользователю наиболее схожие виды с учетом их распространения в качестве подсказки при определении. Изначально ИИ портала сравнивал загруженное фото с базовым набором изображений, который в 2017 г. составлял 859000 фотографий более чем 5000 видов (Horn et al., 2017). Изображения были собраны с камер разного типа и имели разное качество, но при этом определения были многократно проверены. Первичные результаты показывали, что современные на тот момент методы лишь в $67 \%$ давали точное определение, что хорошо иллюстрирует сложность набора данных (Horn et al., 2018a). Еще пару лет назад для большинства растений и животных мира система предлагала названия видов, обитающих в Северной Америке. За год ИИ почти перестал де- 
Таблица 1. Данные по флоре России, собранные на iNaturalist

\begin{tabular}{l|c|c}
\hline & 17.01 .2019 & 08.01 .2020 \\
\hline Число наблюдений & 11004 & 230004 \\
Число видов & 1660 & 5689 \\
Число наблюдателей & 803 & 3858 \\
\hline
\end{tabular}

лать ошибки в растениях Европейской России, несколько хуже он работает в азиатской части и на Кавказе.

Миллионы новых фотографий, проверяемых экспертным сообществом, непрерывно пополняют библиотеку стандартных изображений, позволяя ИИ совершенствоваться. Его возможности пока уступают экспертным оценкам в отдельных группах живых организмов или по отдельным территориям. Тем не менее общая осведомленность системы по флоре мира многократно превосходит знания отдельного эксперта-ботаника. Во многом именно эта особенность iNaturalist привлекает как любителей, так и профессионалов. Успехи iNaturalist сделали возможным дальнейшее применение ИИ для опознавания видов по десяткам миллионов изображений в базе GBIF (Robertson et al., 2019).

Портал по флоре России. Для сбора данных о распространении растений в Москве 29.12.2018 сотрудники МГУ организовали на iNaturalist портал “Флора Москвы". Положительный отзыв пользователей и всплеск интереса заставил организаторов по такой же схеме создать 85 региональных порталов с общей идеологией и объединить их в составе проекта "Флора России" (https://www.inaturalist.org/projects/flora-of-russia), который заработал 09.01.2019.

Каждый региональный портал автоматически включает в свой состав наблюдения по сосудистым растениям, которые были загружены на iNaturalist, достигли “исследовательского уровня" и были сделаны в административных границах этого субъекта федерации. На главной странице каждого регионального портала отображается его базовая статистика и вся основная информация.

На общем портале “Флора России” на главной странице имеется табло с рейтингом региональных проектов (по числу наблюдений, видов, участников), базовая статистика, краткое описание проекта, ленты последних наблюдений и новостей, облако точек всех региональных проектов на общей карте. По ссылкам можно посмотреть рейтинг топ-наблюдателей (по числу сделанных наблюдений или найденных видов), сведения по наиболее часто регистрируемым видам, развернутые статистические отчеты. Таким образом, и региональные проекты, и общероссийский портал организованы в виде рейтинговых таблиц, что стимулирует как личную, так и групповую активность наблюдателей.

Эксперты проекта (многие из которых являются авторами этой статьи) изучают загруженные, но пока неопределенные наблюдения, и подтверждают (или опровергают) мнение автора фотографии, предлагая верное название таксона. Как правило, большинство четко снятых фотографий получают определения в течение нескольких часов после загрузки.

\section{РЕЗУЛЬТАТЫ И ОБСУЖДЕНИЕ}

Общие данные по флоре России на iNaturalist. На момент создания портал “Флора России” объединил все наблюдения, которые уже были на iNaturalist и отвечали требованиям проекта (табл. 1, рис. 1). С той поры данные выросли многократно в 21 раз по числу наблюдений, в 3.4 раза по числу зарегистрированных видов, в 4.8 раз по числу наблюдателей. За год пользователи добавили 220000 новых наблюдений - фотосвидетельств произрастания вида $x$ в точке $y$ в момент времени $t$.

Пользователи, узнав о проекте, не только включились в работу по полевым наблюдениям по флоре России, но и стали активно загружать на портал свои архивы. Так, на 08.01.2020 67711 наблюдений (29.4\%) были сделаны до начала 2019 г. Пик наблюдений в сезон 2019 г. пришелся на летние месяцы - июль (22.2\% от всех наблюдений года), август (20.7\%) и июнь (20.0\%).

По данным GBIF портал iNaturalist занимает третье место по числу записей с территории России (табл. 2). При этом на $63 \%$ он состоит из сведений о распространении сосудистых растений, полученных из проекта “Флора России” (177523 записи). Только США, Канада и Новая Зеландия имеют более полные данные о разнообразии растений, собранные сообществом iNaturalist и экспортированные в GBIF.

B GBIF попадают только наблюдения, достигшие "исследовательского уровня" и имеющие свободную лицензию. В результате работы экспертов доля надежно определенных наблюдений по сосудистым растениям России выросла до $89 \%$, в то время как во всем iNaturalist (в глобальном масштабе и по всем группам живых организмов) доля наблюдений "исследовательского уровня" держится на уровне 61\%. Мы пропагандируем среди участников свободное лицензирование данных для дальнейшего научного использования, в результате чего потеря данных из-за жестких лицензий составляет в нашем проекте всего 20\%. В среднем по миру эта доля гораздо выше - $41 \%$ блокируется несвободными лицензиями, что заметно отличает “Флору России” от остального сообщества iNaturalist. 
Региональные особенности и диспропорции. Россия - огромная страна с неравномерной плотностью населения. Мы проанализировали данные проекта для выявления географической диспропорции в представленных данных по числу наблюдений, видов и участников. Мы использовали официальные данные по площади регионов и численности населения, а также оригинальные данные по богатству региональных флор субъектов РФ. Полная статистическая информация о состоянии данных проекта "Флора России" (на 09.01.2020) в виде электронного приложения к настоящей статье опубликована по адресу https://www.inaturalist.org/journal/apseregin/30522flora-of-russia-09-01-2020 и состоит из 16 таблиц.

Число наблюдений. Ключевым показателем проекта “Флора России” является число загруженных наблюдений. Со второй половины 2019 г. на первое место вышла Москва (24 891 наблюдение). Далее идут Московская обл., Приморский край, Брянская обл., Алтайский край. Первые 10 региональных порталов в сумме обеспечивают $55.5 \%$ данных всего проекта, однако внутри регионов-лидеров ярко проявляется неоднородность пространственной выборки (рис. 2). Менее 100 наблюдений сделано в Магаданской обл., Чечне, Opловской обл., Ненецком АО, Хабаровском крае, Северной Осетии, Туве, Ингушетии, Калмыкии и Еврейской АО.

Число наблюдений на число жителей. Если нормировать число наблюдений на 1000 жителей, то окажется, что самое активное сообщество находится в Камчатском крае. Далее следуют Брянская обл., Чувашия и Приморье. Этот показатель лучше всего отражает одновременно как вовлеченность жителей региона в проект "Флора России”, так и активность именно этого регионального сообщества. Далее следуют Республика Алтай, Севастополь, Ярославская обл., Алтайский край, Чукотка и Калининградская обл.

Плотность наблюдений. Пространственная выборка данных лучше всего характеризуется плотностью наблюдений на стандартную площадь (например, на 1000 км²). Здесь далеко впереди три города федерального значения - Москва (9719 наблюдений), Севастополь (3634), Санкт-Петербург (1908). Далее идут Чувашия, Подмосковье и Брянская обл. с очень активными сообществами при относительно небольшой площади.

Число наблюдений на один вид. Интегральным показателем, который лучше всего характеризует как плотность данных, так и выявленность флоры регионов, является число сделанных наблюдений на один обнаруженный вид. Накопление большого числа наблюдений постепенно приводит к выявлению состава флоры (или, как минимум, регулярно встречающихся видов). Когда новые виды перестают прибавляться, а активное сообщество
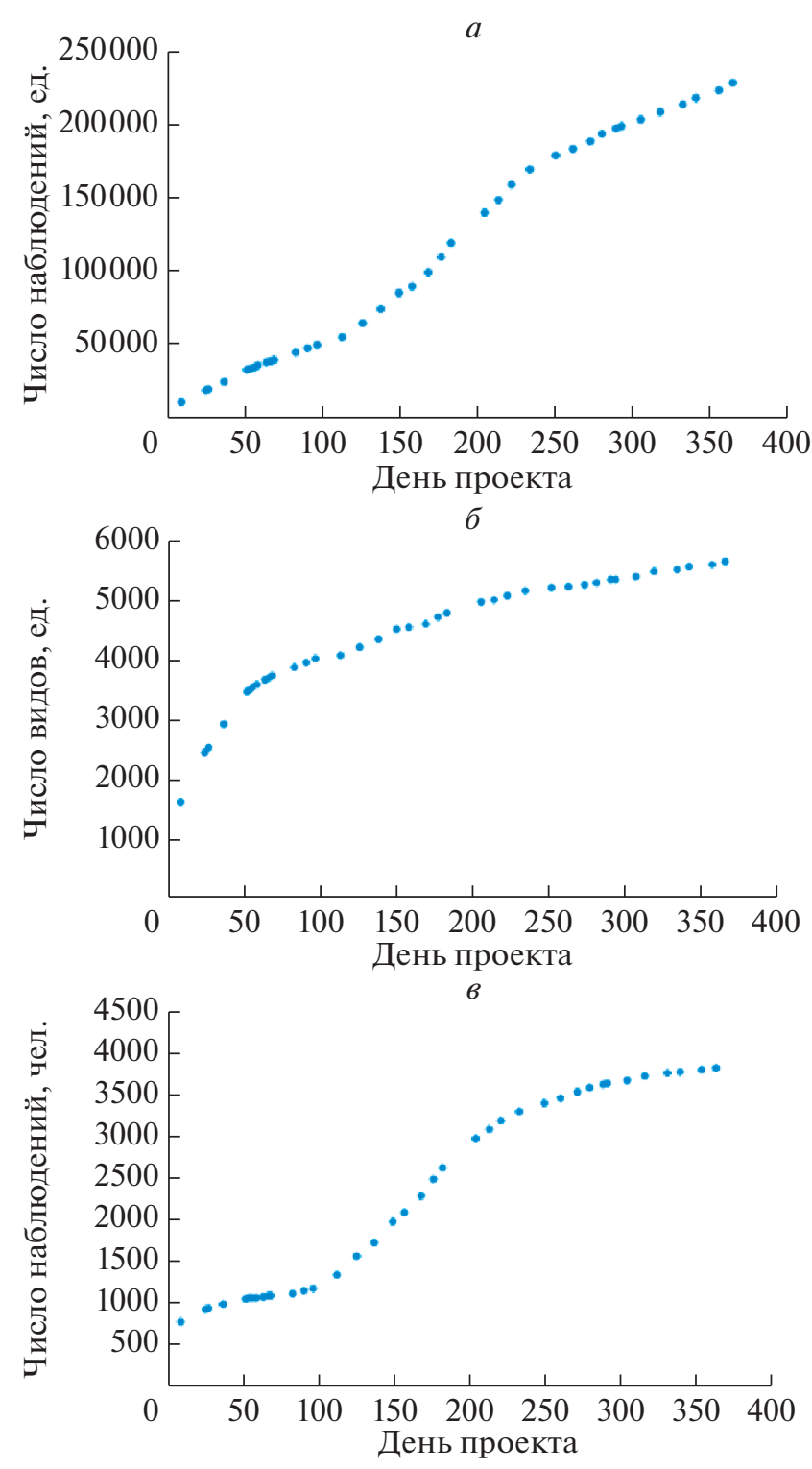

Рис. 1. Базовая статистика портала “Флора России": $a$ - число наблюдений; $\sigma$ - число видов; $в-$ число пользователей.

делает все новые наблюдения, показатель среднего числа наблюдений на один вид начинает стремительно расти. По этому показателю лидируют Москва (25 наблюдений), Подмосковье (17), Чувашия (15) и Брянская обл. (13). Богатые региональные флоры (например, горные) проигрывают относительно бедным равнинным, но ведь именно там и нужно делать больше наблюдений, чтобы выявить редкие виды.

Число выявленных видов. Отметим лидерство Дагестана (1557 видов), Приморья (1376), Крыма (1109), Брянской обл. (1036), Алтайского края (1025). Согласно схемам Л.И. Малышева (1992), самые богатые участки в России по числу видов (в 
Таблица 2. Ведущие массивы открытых электронных данных по биоразнообразию России

\begin{tabular}{r|l|c}
\hline № & \multicolumn{1}{|c}{ Название массива } & \multicolumn{1}{|c}{ Число } \\
записей \\
\hline 1 & Moscow University Herbarium (MW) (Seregin, 2020) & 623089 \\
\hline 2 & RU-BIRDS.RU, Birds observations database from Russia and neighboring regions (Ukolov et al., 2019) & 300571 \\
\hline 3 & iNaturalist Research-grade Observations (iNaturalist.org, 2020) & 280721 \\
\hline 4 & Geographically tagged INSDC sequences (European Nucleotide Archive, 2019) & 195599 \\
\hline 5 & EOD - eBird Observation Dataset (Levatich, Padilla, 2019) & 171034 \\
\hline 6 & A grid-based database on vascular plant distribution in Vladimir Oblast, Russia (Seregin, 2017) & 123054 \\
\hline 7 & Chronicle of Nature - Phenology of Plants of Zhiguli Nature Reserve (Kiseleva, 2019) & 86524 \\
\hline 8 & EBCC Atlas of European Breeding Birds (Hagemeyer et al., 2016) & 80923 \\
\hline 9 & A global database for the distributions of crop wild relatives (Centro Internacional..., 2018) & 69255 \\
\hline 10 & Arctic Ocean Diversity (Alaska Ocean..., 2018) & 62946 \\
\hline
\end{tabular}

пересчете на стандартную площадь в $10000 \mathrm{KM}^{2}$ ) это как раз Крым, Кавказ, Горный Алтай и крайний юг Приморья. Статистика проекта в целом отражает эти ботанико-географические закономерности.

Доля выявленных видов. Если рассматривать число известных в каждом регионе видов, то по доле представленных растений лидируют Ярославская обл. (73\% от 1042), Брянская обл. (71\% от 1451 видов), Нижегородская обл. (69\% от 1290), Камчатский край (58\% от 1300) и Татарстан (56\% от 1610). Еще четыре региона имеют показатель выше $50 \%$.

Число наблюдателей. Больше всего участников отметилось в Подмосковье и Москве. При почти совпадающем их числе (чуть более 700 человек), в этих регионах списки наблюдателей совпали только на треть. В целом, Москва с Подмосковьем и Санкт-Петербург с Ленинградской обл. в лидерах вместе с курортными черноморскими регионами (Краснодарский край, Крым). По-настоящему обширные сообщества сформировались в Нижегородской и Свердловской обл., хотя и здесь все “крутится" вокруг городов-миллионников.

Площ,адь, приходящаяся на одного наблюдателя. Этот показатель позволяет оценить, где действительно много участников вовлечено в проект “Флора России” в пересчете на площадь региона. По числу квадратных километров, приходящихся на одного наблюдателя, безусловно лидируют Москва, Санкт-Петербург, Севастополь (4-7 км²). Уже в Московской обл. этот показатель возрастает до 63 км², далее идут Республика Крым (131 км²), Калининградская обл. (199 км²), Адыгея (229 км²).

Число наблюдений на одного наблюдателя. Этот показатель хорошо демонстрирует, в каких регионах данные поступают в основном от немногих са- мых активных участников. Именно активные одиночки помогли высоко подняться Омской обл., Приморскому краю, Чувашии, Брянской обл., Дагестану и Камчатскому краю.

Вклад в “Атлас флоры России". Проект “Флора России" на iNaturalist создавался, во многом, как инструмент сбора оперативных данных о разнообразии растений для атласа флоры России, подготовка которого началась на базе Цифрового гербария МГУ (Seregin, 2018). Сведения о распространении видов в атласе флоры России, основанном на точечных данных (точки сбора гербарных образцов, отдельных наблюдений, описания локальных флор, геоботанических описаний), можно будет агрегировать по любым выделам. С этой точки зрения вклад проекта “Флора России" на iNaturalist в общую копилку геоданных по флоре страны трудно переоценить.

За последние годы Гербарий Московского университета вкладывает ежегодно в фонды по 20000 образцов, но лишь 5000-10000 из них это свежие сборы, документирующие современное разнообразие растений. При этом Гербарий МГУ является наиболее активно растущим гербарием России (Серегин, 2017). Фактически, загруженные участниками за год фотосвидетельства (220000 наблюдений) в несколько раз превышают все гербарные сборы, сделанные ботаниками России за этот сезон. Разумеется, фотография не может заменить гербарный образец, а большинство авторов этой статьи - “классические” флористы, которые продолжают собирать гербарные материалы.

Однако опыт этого года показал: современные технологии позволяют нам эффективно собирать, быстро обрабатывать, стремительно публиковать и в удобном виде выгружать для использования строго научные данные о распространении большинства видов флоры России в виде цифро- 

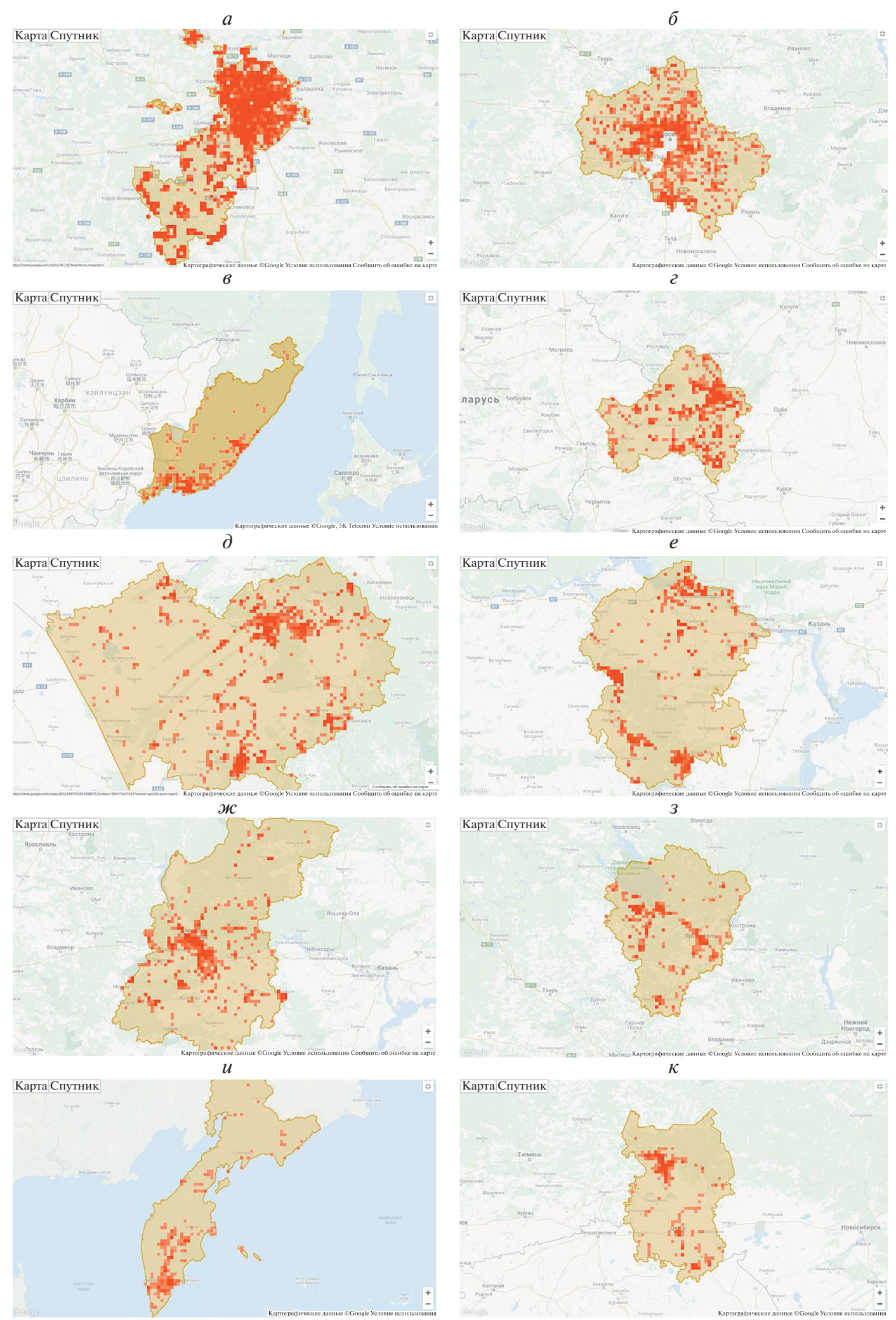

Рис. 2. Пространственная неоднородность данных на территории регионов-лидеров портала “Флора России” (сеточные данные): $a$ - Москва (24891 наблюдение), $\sigma$ - Московская обл. (16875), в - Приморский край (15992), 2 - Брянская обл. (13065), $\partial-$ Алтайский край (12796), $e$ - Чувашия (11170), жж- Нижегородская обл. (10240), 3 - Ярославская обл. (8847), и - Камчатский край (6858), $к$ - Омская обл. (6826). Данные на 08.01.2020. 
$a$
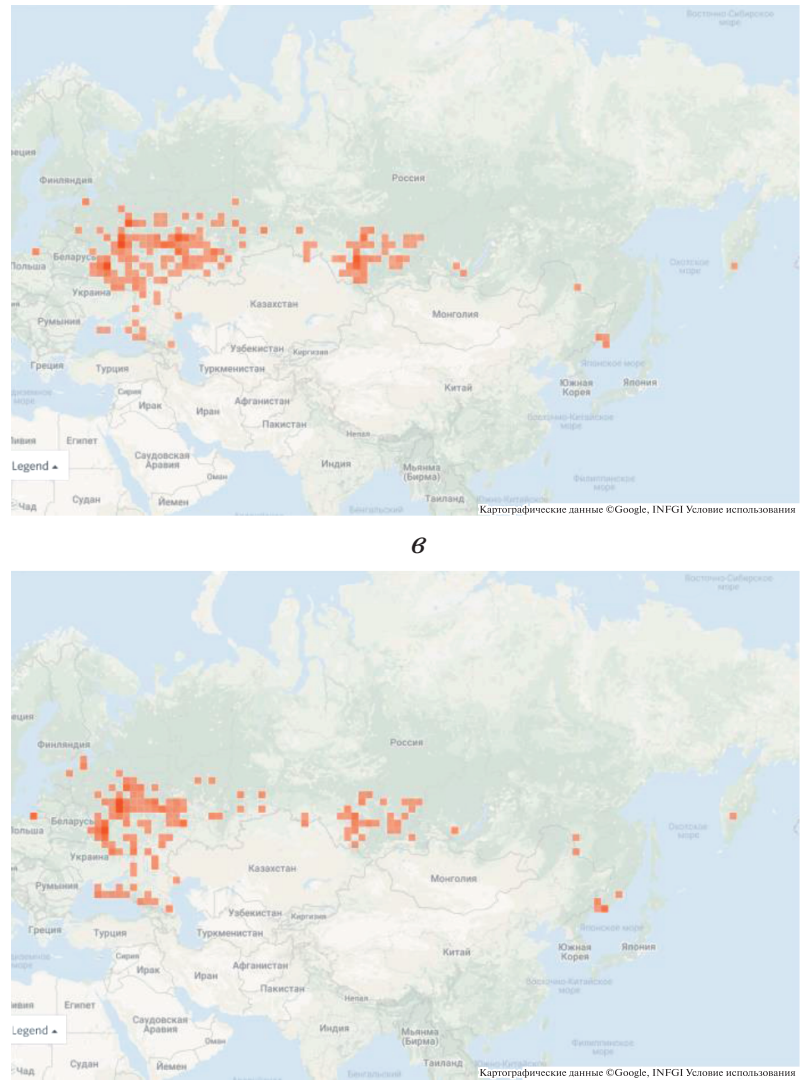

$\sigma$
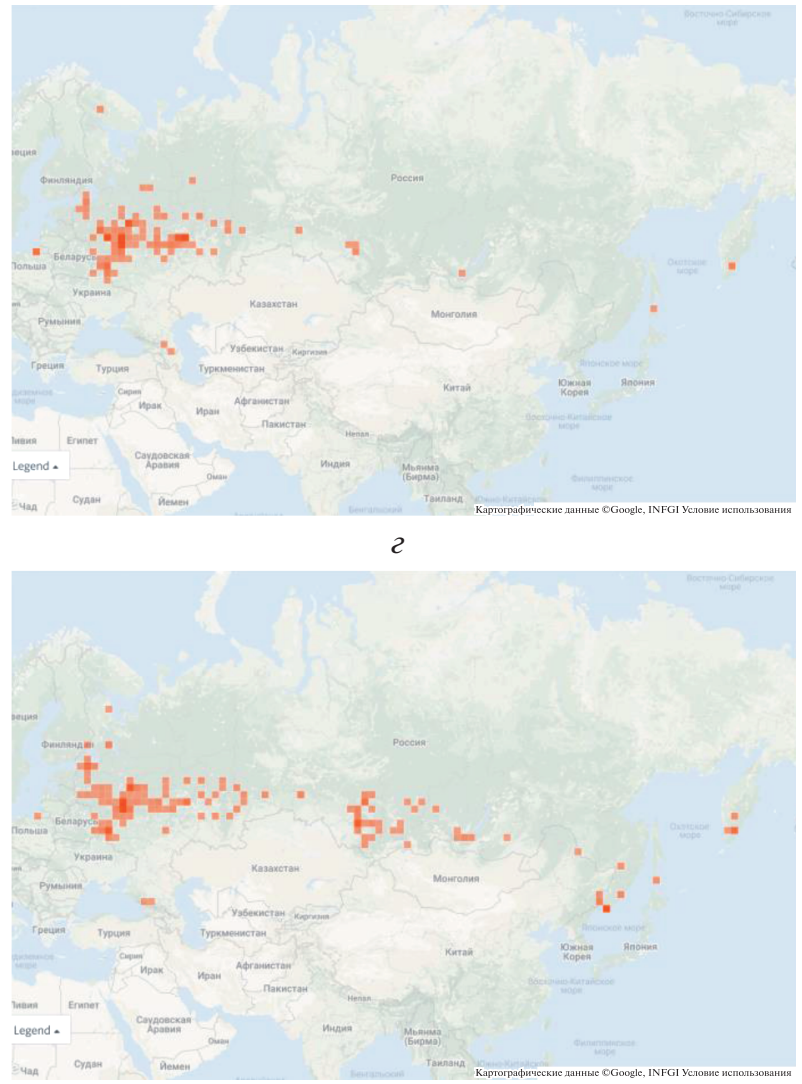

Рис. 3. Самые распространенные адвентивные виды флоры России по данным портала “Флора России" (сеточные данные): $a$ - Acer negundo (1 461 точка), $\sigma$ - Heracleum sosnowskyi (830; двумя точками на Кавказе (Дагестан) отмечены природные популяции вида), в - Erigeron canadensis (700), г - Impatiens glandulifera (664). Данные на 08.01.2020.

вых фотографий. Современные смартфоны снабжают фотографии точными координатами, а изображения с фотоаппаратов могут в два клика дополняться координатами, которые в виде трека записывает лежащий в кармане навигатор. Ocoбенно необходимо отметить фоторегистрацию обычных видов, которые не всегда привлекают внимание ботаников.

Расселение адвентивных видов. Из числа 100 наиболее регистрируемых видов проекта "Флора России” девять относятся к числу адвентивных (заносных), т.е. чуждых флоре России или большей ее части. Это, прежде всего, инвазивные виды: Acer negundo (1461 точка), Heracleum sosnowskyi (830), Erigeron canadensis (700), Impatiens glandulifera (664), Impatiens parviflora (609), Lupinus polyphyllus (563), Matricaria discoidea (464), Echinocystis lobata (461), Erigeron annuиs (458).

Заносные виды чаще растут в нарушенных местообитаниях, близ путей сообщения и жилья, а потому являются доступным объектом для регулярной документации встреч. Например, в самом популярном региональном проекте по флоре Москвы сразу три адвентивных вида входят в число
20 самых часто отмечаемых растений. Постоянный скрупулезный мониторинг расселения адвентивных видов, числа их популяций и регистрация новых встреч являются основой возможных мероприятий по регуляции их численности и охране природных сообществ от внедрения чужеродных видов. Расселение некоторых растений происходит столь стремительно, что публикуемые в научных изданиях сведения быстро отстают от меняющейся картины их распространения. Карты распространения большинства заносных видов растений, которые созданы и пополняются участниками проекта, являются наиболее адекватными (а зачастую и единственными) картами ареалов этих растений на сегодняшний день (рис. 3). Они обновляются в режиме реального времени по мере загрузки данных.

\section{ЗАКЛЮЧЕНИЕ}

За один год всем, кто публикует данные о распространении сосудистых растений России на iNaturalist, удалось собрать 220000 записей по 5689 видам флоры страны. Еще 29000 фотонаблюдений по разным причинам пока не опреде- 
лены. Наиболее активные и сведущие участники, сфотографировав все встреченные виды растений близ мест, где они живут, с разной степенью полноты задокументировали десятки локальных флор. Для многих муниципальных районов полученные списки видов представляют собой самые полные и точные флористические данные.

Еще в конце 2018 г. iNaturalist включал лишь 47888 наблюдений из России (18-е место в мире; $0.7 \%$ ), а годом ранее - 4555 (39-е место; 0.1\%) (https://www.inaturalist.org/stats/2018). По итогам 2019 г. Россия стремительно взлетела вверх - на территории нашей страны было сделано 383987 наблюдений (6-е место; 2.9\%). Столь заметный рост открытых электронных данных о биоразнообразии страны в самое последнее время был получен, во многом, в результате реализации проекта "Флора России" на iNaturalist.

Нашими усилиями Россия получила третий по объемам массив данных по биоразнообразию, опубликованный в GBIF. Динамика проекта позволяет предположить, что в течение пары лет он станет самым большим. Любой пользователь может скачать этот массив в табличном виде через GBIF или напрямую через iNaturalist и использовать в своих исследованиях.

Созданный (только за первый год проекта) задел позволяет подойти к созданию атласа флоры России именно со стороны краудсорсинга в результате тесного взаимодействия профессиональных экспертов-ботаников и любителей природы, которые тратят свое время, силы и посильные средства на документацию биоразнообразия самой большой страны мира.

Исследование выполнено при финансовой поддержке РФФИ и Правительства Москвы в рамках научного проекта № 19-34-70018. Проект “Флора России” объединил 3858 наблюдателей, опубликовавших свои фотонаблюдения на iNaturalist. В число авторов статьи вошли наиболее активные участники (подписчики) проекта, одновременно входящие как в число топ-наблюдателей, так и в число наиболее активных экспертов. Выражаем нашу искреннюю признательность всем участникам общероссийского и каждого из 85 региональных проектов, особенно тем, кто не смог выступить в качестве соавтора. Все статистические данные в статье приведены на 08.01.2020.

\section{СПИСОК ЛИТЕРАТУРЫ}

Малышев Л.И., 1992. Биологическое разнообразие в пространственной перспективе // Биологическое разнообразие: подходы к изучению и сохранению. СПб. С. 41-52.

Серегин А.П., 2017. Гербарий Московского университета (MW) сегодня: фонды, онлайн доступ и научная работа // Бот. журн. Т. 102. № 3. С. 281-308.
Alaska Ocean Observing System, 2018. Arctic Ocean Diversity. GBIF.org. Occurrence dataset https://doi.org/10.15468/xrzanm.

Bonney R., Cooper C.B., Dickinson J., Kelling S., Phillips T. et al., 2009. Citizen science: A developing tool for expanding science knowledge and scientific literacy // BioScience. V. 59. № 11. P. 977-984.

Centro Internacional de Agricultura Tropical (CIAT), 2018. A global database for the distributions of crop wild relatives. Version 1.12. GBIF.org. Occurrence dataset https://doi.org/10.15468/jyrthk.

Cui Y., Song Y., Sun C., Howard A., Belongie S., 2018. Large Scale Fine-Grained Categorization and Domain-Specific Transfer Learning // The IEEE Conference on Computer Vision and Pattern Recognition (CVPR). Salt Lake City. P. 4109-4118.

European Nucleotide Archive (EMBL-EBI), 2019. Geographically tagged INSDC sequences. GBIF.org. Occurrence dataset https://doi.org/10.15468/cndomv.

Fourcade Y., 2016. Comparing species distributions modelled from occurrence data and from expert-based range maps. Implication for predicting range shifts with climate change // Ecol. Inform. V. 36. P. 8-14.

Hagemeyer W., Blair M., Loos W., 2016. EBCC Atlas of European Breeding Birds. Version 1.3. European Bird Census Council (EBCC). GBIF.org. Occurrence dataset https://doi.org/10.15468/adtfvf .

Hand E., 2010. Citizen science: People power // Nature. V. 466. № 7307. P. 685-687.

Horn G., van, Mac Aodha O., Song Y., Shepard A., Adam H. et al., 2017. The iNaturalist challenge // arXiv. preprint arXiv.1707.06642.

Horn G., van, Branson S., Loarie S., Belongie S., Perona P., 2018a. Lean Multiclass Crowdsourcing // The IEEE Conference on Computer Vision and Pattern Recognition (CVPR). Salt Lake City. P. 2714-2723.

Horn G., van, Mac Aodha O., Song, Y., Cui Y., Sun C. et al., 2018b. The iNaturalist Species Classification and Detection Dataset // The IEEE Conference on Computer Vision and Pattern Recognition (CVPR). Salt Lake City. P. 8769-8778.

iNaturalist.org, 2020. iNaturalist Research-grade Observations. GBIF.org. Occurrence dataset https://doi.org/10.15468/ab3s5x.

Kiseleva D., 2019. Chronicle of Nature - Phenology of Plants of Zhiguli Nature Reserve. I.I. Sprygin Zhiguli State Nature Biosphere Reserve. GBIF.org. Occurrence dataset https://doi.org/10.15468/ecfeiu.

Levatich T., Padilla F., 2019. EOD - eBird Observation Dataset. Cornell Lab of Ornithology. GBIF.org. Occurrence dataset https://doi.org/10.15468/aomfnb.

Longbottom J., Shearer F.M., Devine M., Alcoba G., Chappuis $F$. et al., 2018. Vulnerability to snakebite envenoming: A global mapping of hotspots // Lancet. V. 392. № 10148. P. 673-684.

Nyegaard T., 2019. DOF - Observations from the Danish Ornithological Society. Danish Ornithological Society. GBIF.org. Occurrence dataset https://doi.org/10.15468/tww7cj.

Ocampo-Peñuela N., Winton R.S., Wu C.J., Zambello E., Wittig T.W., Cagle N.L., 2016. Patterns of bird-window collisions inform mitigation on a university campus // PeerJ. V. 4. P. e1652. 
Robertson T., Belongie S., Adam H., Kaeser-Chen C., Zhang C. et al., 2019. Training machines to identify species using GBIF-mediated datasets // Biodivers. Inf. Sci. Stand. V. 3. P. e37230.

Seregin A.P., 2017. A grid-based database on vascular plant distribution in Vladimir Oblast, Russia. Lomonosov Moscow State University. GBIF.org. Occurrence dataset https://doi.org/10.15468/hoafrr.

Seregin A.P., 2018. The largest digital herbarium in Russia is now available online! // Taxon. V. 67. № 2. P. 463-467.

Seregin A.P., 2020. Moscow University Herbarium (MW). Version 1.114. Lomonosov Moscow State University. GBIF.org. Occurrence dataset https://doi.org/10.15468/cpnhcc.

Shah M., Coulson S., 2020. Artportalen (Swedish Species Observation System). Version 92.172. ArtDatabanken. GBIF.org. Occurrence dataset https://doi.org/10.15468/kllkyl.

Silvertown J., 2009. A new dawn for citizen science // Trends Ecol. Evol. V. 24. № 9. P. 467-471.
Spear D.M., Pauly G.B., Kaiser K., 2017. Citizen Science as a Tool for Augmenting Museum Collection Data from Urban Areas // Front. Ecol. Evol. V. 5. P. 86.

The Norwegian Biodiversity Information Centre, Hoem S., 2020. Norwegian Species Observation Service. Version 1.74. The Norwegian Biodiversity Information Centre (NBIC). GBIF.org. Occurrence dataset https://doi.org/10.15468/zjbzel.

Ukolov I., Kalyakin M., Voltzit O., 2019. RU-BIRDS.RU, Birds observations database from Russia and neighboring regions. Zoological Museum of M.V. Lomonosov Moscow State University. Version 1.4. Lomonosov Moscow State University. GBIF.org. Occurrence dataset https://doi.org/10.15468/5cjx70.

Vries H., de, 2018. Observation.org, Nature data from the Netherlands. GBIF.org. Occurrence dataset https://doi.org/10.15468/5nilie.

White R.L., Sutton A.E., Salguero-Gómez R., Bray T.C., Campbell H. et al., 2015. The next generation of action ecology: Novel approaches towards global ecological research // Ecosphere. V. 6. № 8. P. 1-16.

\section{"Flora of Russia" on iNaturalist: Big data on biodiversity of a big country}

\section{A. P. Seregin ${ }^{a}$ *, D. A. Bochkov ${ }^{a}$, Ju. V. Shner ${ }^{a}$, E. V. Garin ${ }^{b}$, S. R. Mayorov ${ }^{a}$, P. V. Goliakov ${ }^{c}$,} B. V. Bolshakov ${ }^{d}$, V. E. Prokhorov ${ }^{e}$ M. M. Mallaliev $f$, G. M. Vinogradov ${ }^{g}$, Alexandr L. Ebel ${ }^{h}$,

E. S. Kashirina ${ }^{i}$, O. V. Biryukova ${ }^{j}$, O. P. Kuryakova ${ }^{d}$, S. V. Mirvoda ${ }^{k}$, A. N. Khimin $l$, R. A. Murtazalievf, V. N. Zelenkova ${ }^{m}$, S. V. Dudov ${ }^{a}$, M. S. Gorbunova ${ }^{n}$, S. V. Gerasimov ${ }^{o}$, Aleksei L. Ebel ${ }^{p}$, V. P. Travkin ${ }^{d}$, O. A. Chernyagina $q$, E. A. Razina ${ }^{d}$, A. P. Zyryanov ${ }^{d}$, D. V. Tretyakovar ${ }^{r}$, S. A. Lednev ${ }^{a}$, V. Yu. Teploukhovs, D. V. Kuzmenckin ${ }^{c}$, M. M. Krivosheevt ${ }^{t}$ E. S. Popov ${ }^{u}$, R. R. Sultanov ${ }^{d}$, Yu. M. Basov ${ }^{d}$, K. V. Dudova ${ }^{a}$, D. V. Tishin ${ }^{e}$, A. A. Yakovlev ${ }^{d}$, Yu. V. Danilevsky ${ }^{d}$, I. N. Pospelov ${ }^{v}$, A. N. Kandaurova ${ }^{d}$, S. B. Kutueva ${ }^{w}$, D. A. Yumagulov ${ }^{d}$, K. V. Samodurow ${ }^{d}$, L. Ya. Smirnova ${ }^{d}$, U. V. Bury ${ }^{x}$, V. E. Yusupov ${ }^{d}$, D. V. Epikhin $y$, T. G. Repina ${ }^{d}$, E. I. Boginsky ${ }^{d}$, A. V. Dubynin ${ }^{z}$, A. V. Korobkov ${ }^{d}$, D. V. Nesterkovaa ${ }^{a a}$, A. V. Poluyanov ${ }^{b b}$, A. V. Danilin ${ }^{c c}$, A. N. Efremov ${ }^{d d}$, L. V. Pozhidaeva ${ }^{e e}$, A. V. Verkhozina ${ }^{f f}$, Yu. A. Postnikov ${ }^{n}$, E. A. Linnik ${ }^{d}$, I. A. Kobuzeva ${ }^{d}$, S. V. Prokopenko ${ }^{g g}$, E. A. Shumikhina ${ }^{h h}$, M. A. Kushunina ${ }^{a}$, I. V. Kuzmin ${ }^{i i}$, L. M. Rasrani D. V. Sukhova ${ }^{a}$, A. V. Popov ${ }^{k k}$

${ }^{a}$ Lomonosov Moscow State University Leninskiye Gory, 1, Moscow, 119991 Russia

${ }^{b}$ Papanin Institute for Biology of Inland Waters, RAS

Borok, Nekouzsky Distr., Yaroslavl Region, 152742 Russia

${ }^{c}$ Tigirek State Natural Reserve

Nikitina str., 111-42, Barnaul, 656043 Russia

${ }^{d}$ Independent Researcher, Moscow, Russia

${ }^{e}$ Kazan Federal University

Kremlevskaya, 18, Kazan, 420100 Russia

${ }^{f}$ Mountain Botanical Garden of the Dagestan Scientific Centre, RAS

M. Gadzhiyev, 45, Makhachkala, 367000 Russia

${ }^{g}$ Shirshov Institute of Oceanology, RAS

Nakhimovsky Pr., 36, Moscow, 117997 Russia

${ }^{h}$ Tomsk State University

Pr. Lenina, 36, Tomsk, 634050 Russia

${ }^{i}$ Lomonosov Moscow State University, Branch in Sevastopol

Geroyev Sevastopolya, 7, Sevastopol, 299001 Russia

${ }^{j}$ Lobachevsky Nizhny Novgorod State University

Pr. Gagarina, 23, Nizhnij Novgorod, 603950 Russia

${ }^{k}$ Agricultural Public Joint Stock Company

Belorechensky Village, Irkutsk Region, 665479 Russia

'Pavlovsk Secondary School № 2

Kirova, 27/1, Pavlovsk, Voronezh Region, 396420 Russia 
${ }^{m}$ Belgorod State National Research University Pobedy, 85, Belgorod, 308015 Russia

${ }^{n}$ Moscow Pedagogical State University

M. Pirogovskaya, 1, Moscow, 119435 Russia

${ }^{o}$ Republican Children's Ecological and Biological Center Pr. Oktyabrya, 4, Ufa, 450001 Russia

${ }^{p}$ Altai State University

Pr. Lenina, 61, Barnaul, 656049 Russia

${ }^{q}$ Kamchatka Division of Pacific Institute of Geography, Far East Branch of RAS

Partizanskaya, 6, Petropavlovsk-Kamchatskiy, 683000 Russia

${ }^{r}$ Togliatti State University

Belorusskaya, 14, Togliatti, Samara Region, 445020 Russia

${ }^{s}$ Main Department of Forestry, Omsk Region

Kuibysheva, 63, Omsk, 644001 Russia

${ }^{t}$ Bashkir State University

Z. Validi, 32, Ufa, 764500 Russia

${ }^{u}$ Komarov Botanical Institute, $R A S$

Prof. Popov, 2, St. Petersburg, 197376 Russia

${ }^{v}$ Severtsov Institute of Ecology and Evolution, RAS

Leninsky Pr., 33, Moscow, 119017 Russia

${ }^{w}$ Rybinsk State Historical, Architectural and Art Museum Preserve

Volzhskaya Emb., 2, Rybinsk, Yaroslavl Region, 152901 Russia

${ }^{x}$ Belorussian State University

Nezavisimosti Av., 4, Minsk, 220030 Republic of Belarus

${ }^{y}$ Vernadsky Crimean Federal University Academician

Vernadsky Pr., 4, Simferopol, 295007 Russia

${ }^{z}$ Open Laboratory of Conservation Biology

Irtyshskaya, 33, Novosibirsk, 630060 Russia

${ }^{a}$ Institute of Plant and Animal Ecology, Ural Branch of RAS

8th March str., 202, Yekaterinburg, 620144 Russia

${ }^{b b}$ Kursk State University

Radischeva, 33, Kursk, 305000 Russia

${ }^{c c}$ National Research Technological University “MISiS”

Leninsky Pr., 2, Moscow, 119049 Russia

${ }^{d d}$ Design Institute for Oil and Gas Projects Construction and Rehabilitation

Krasnyi Put str., 153/2, Omsk, 644033 Russia

ee Altai Regional Public Community "Environmental Asset”

A. Petrov str., 247a-44, Barnaul, 656065 Russia

${ }^{f f}$ Siberian Institute of Plant Physiology and Biochemistry, Siberian Branch of RAS

Lermontova, 132, Irkutsk, 664033 Russia

${ }^{g g}$ Federal Scientific Center of the East Asia Terrestrial Biodiversity, Far East Branch of RAS

Pr. 100 Let Vladivostoku, 159, Vladivostok, 690022 Russia

hh "Promneftegazecologia”, Ltd

Respubliki St., 207, Tyumen, 625019 Russia

ii Tyumen State University

Volodarskogo, 6, Tyumen, 625003 Russia

${ }^{i j}$ Die Universität für Bodenkultur Wien

Gregor-Mendel-Straße, 33, Vienna, A-1180 Austria

${ }^{k}$ Volgograd State Social and Pedagogical University

Pr. Lenina, 27, Volgograd, 400066 Russia

*e-mail: botanik.seregin@gmail.com

The "Flora of Russia" project on iNaturalist brought together professional scientists and amateur naturalists from all over the country. Over 3800 people participate in data collection. In one year, the participants collected over 220000 photo observations on 5689 species of the Russian flora. This is the third largest dataset of open distributional data on the country's biodiversity (and the second largest for plants), a leading source of data on the current state of the nation's flora. For most alien species, the resulting maps are the most reliable distribution maps within Russia. For many municipalities, the resulting species lists are the most complete and accurate floristic information. All project data are available under free licenses and can be freely used in scientific, educational and environmental activities. 